\title{
Hacia una nueva condición histórica
}

\author{
François Hartog ${ }^{1}$ \\ Traducción de \\ Miriam Hernández Reyna ${ }^{2}$ 'Towards a new historical condition
}

Este título, evidentemente demasiado ambicioso, tomémoslo como hipótesis, preguntándonos si los cambios recientes y en curso de nuestras experiencias históricas apuntan hacia una nueva condición histórica. La historia-disciplina apenas podría captarla, porque ella misma ya no sería exactamente la que desde hace mucho tiempo hemos asociado con el mundo y los tiempos modernos: la de una progresiva toma de conciencia de un "despliegue del conjunto de la experiencia humana y social en el tiempo" (Gauchet, 2003:10). Como experiencia histórica designamos, simplemente, "las diferentes formas en que las personas, bajo el horizonte de sus mundos sociales históricamente constituidos, van imaginando y se representan a sí mismos el pasado y sus significaciones para el presente" (Palmié y Stewart, manuscrito).

De ahí esta primera constatación, sobre la cual todo mundo, practicante o no de la disciplina histórica, puede con facilidad estar de acuerdo. Hoy en día tienen lugar múltiples usos del pasado: desde los más oficiales a lo más lúdicos, de los más instrumentalizados a los más distanciados.

1 Director de estudios en la Escuela de Altos Estudios en Ciencias Sociales de París. Es autor, principalmente, de Regímenes de historicidad. Presentismo y experiencias de tiempo (publicado en español por la Universidad Iberoamericana en 2007), Memorias de Ulises. Relatos sobre la frontera en la antigua Grecia (publicado en español por el Fondo de Cultura Económica, 2007) y Evidencia de la historia. Lo que ven los historiadores (publicado en español por la Universidad Iberoamericana, 2011), entre otros. Su obra más reciente es Partir pour la Grèce (Flammarion, 2015).

2 Título original: "Vers une nouvelle condition historique", artículo publicado en la revista Le Débat, enero de 2016, núm. 188 (Gallimard, París). 
Si bien el fenómeno no es nada nuevo, sin embargo el espectro de formas en que se presenta se ha ampliado considerablemente. Porque nuestras capacidades de producir pasados se han incrementado (Gruzinski, 2015; Rioux, 2015). Porque podemos ir desde las grandes conmemoraciones, tan presentes en el curso del año 2014 en Europa, con sus puestas en escena de la palabra pública, que han siempre existido, hasta los juegos de video que permiten a cada quien, en internet o por su cuenta, reproducir los grandes acontecimientos del pasado, incluyendo las películas o las series. Sin ignorar todo lo que a cada instante circula en internet (sitios, foros, blogs y twitter). Sin pasar por alto los medios de comunicación que son ya tradicionales, como la edición. Se agregan, finalmente, la escuela y la universidad como lugares institucionales de aprendizaje, de transmisión y de producción de nuevos conocimientos, a pesar de que ahora nos interrogamos por doquier sobre este tipo de transmisión, es decir, de su ausencia, de sus carencias y de sus dificultades.

Este breve inventario descriptivo es suficiente para mostrar que los modos de aprehensión del pasado (es decir, la materia misma de nuestras experiencias históricas) han cambiado y cambian rápidamente (Hartog, 2010) ¿Qué puede hacer el historiador frente a tal proliferación de pasados, frente a tal multiplicación de la oferta, donde encontramos todo, pero también de todo -incluso, evidentemente, lo execrable-? ¿Fingir ignorarlo, continuar como si nada sucediera? La política del avestruz rara vez ha conducido a la victoria. Frente a historias alternativas, o incluso a alternativas a la historia (que juegan, por ejemplo, a la memoria contra la historia), optar por una palabra de autoridad, del tipo "yo, la Historia, les digo lo que en realidad sucedió", vanagloriándose del lema rankeano, asegurará no ser escuchado más allá del pequeño círculo de la comunidad de historiadores previamente convencidos. ¿Qué queda, entonces? ¿Deplorar esta disgregación del espacio público y esta desaparición de "lugares comunes" (de memorias incompartibles, en lugar y en el lugar de un "pasado compartido"), o, al contrario, felicitarse de esos nuevos espacios (insulares) donde experiencias históricas ignoradas, olvidadas, jamás reformuladas hasta ahora, pueden ser dichas, retomadas o circular? Por lo menos, tomemos consciencia de ello. Pero comencemos por tomar distancia.

\section{El concepto moderno}

de la Historia y sus fallas

La Historia ha sido uno de los nombres de "entrecruce", si no es que el concepto cardinal en torno al que se cristaliza lo creíble de los dos siglos anteriores (Hartog, 2013a). Con una mayúscula, valía por sí como explica- 
ción, es decir, se le dispensaba a menudo de dar una. Con una minúscula, invita a buscar varias explicaciones, ya sea que nos dirijamos al establecimiento de leyes, a la identificación de grandes movimientos de fondo, o al reconocimiento del lugar, más o menos grande, de la contingencia en las cuestiones humanas. Paul Valéry, quien criticó frecuentemente la historia, se libraba de la primera, la Historia con una $\mathrm{H}$ mayúscula. "La palabra tiene dos sentidos decía: La Historia nos enseña... la Historia juzgará... Es un mito hecho de dos tonterías". Para la segunda, con h minúscula, lamentaba que no fuera más que "un conjunto de escrituras". Pero la entrada en una época crítica o de reflexividad no le estaba vedada a él, que no cesó de volver a la cuestión en sus Cahiers. Sea lo que fuere respecto a las posiciones de Valéry, los historiadores se situarían progresivamente en el dominio de la historia con minúscula, que se volvió su "territorio". ${ }^{3}$ Un territorio limitado pero en expansión, con sus "frentes pioneros" y los descensos a las profundidades donde, bajo nombres y formas diferentes, el futuro permanece en el horizonte, más o menos activo o imperativo. En el curso del siglo XIX y de una buena parte del siglo XX, los historiadores negociaron sin cesar con el régimen moderno de historicidad, como lo hicieron, a su modo, los escritores, con los novelistas a la cabeza, privilegiando casi todas las fallas y discordancias de temporalidades. De Balzac a Sartre, pasando por Tolstoï y Musil.

Pero también existe la historia que el escritor George Perec nombró en $W$ ou le souvenir d'enfance, la Historia con su gran hacha, ${ }^{4}$ la que Valéry, a pesar de todos sus ejercicios cotidianos de pensamiento, no había sabido ni ver ni reconocer. "No tengo recuerdos de infancia, escribió Perec, estaba dispensado de ellos: otra historia, la Grande, la Historia con su gran hacha, había ya respondido en mi lugar: la guerra, los campos" (Perec, 1975). ¿Qué decir de esta experiencia? ¿La historia, con o sin mayúscula, podría simplemente retomar su rumbo hacia adelante? (Hartog, 2013b). Desde 1946, Lucien Febvre, que quería creer en ello, exhortaba, en algunas líneas de su manifiesto de Annales nouvelles, a "zambullirse en el agua". Para él, la urgencia, so pena de no comprender nada del mundo mundializado del mañana (es decir, el de hoy), era mirar no hacia atrás, hacia lo que acababa de tener lugar, sino delante de sí, hacia adelante. "El mundo que acabó ayer, se ha terminado para siempre". Si

3

\footnotetext{
"Le territoire de l'historien", es el título de una recopilación de artículos, publicada por Emmanuel Le Roy Ladurie, en 1973, ver Jacques Revel, Un Parcours critique, Douze exercices d'histoire soicale, París, Galaade, 2006, pp. 18-20.

Nota del traductor: el autor juega aquí con la palabra "Hache" que tiene la misma pronunciación que la letra " $H$ " en francés.
} 
nosotros los franceses tenemos una oportunidad de salir adelante, es comprendiendo, más rápido y mejor que otros, esta verdad evidente. Dejando ir los restos del barco, hay que lanzarse al agua, y a nadar, les digo yo" (Febvre, 1992:40). Conviene metabolizar la experiencia de la guerra y encaminarse hacia el futuro haciendo un año cero, es decir, un nuevo punto de partida.

Del lado de la disciplina, se agregarían, entonces, otras capas al hojaldre del concepto historia. El cuestionamiento fue extendido, dando lugar a otras estructuras y después, en los años 1970, a la antropología. Fue, representado por La Méditerranée de Braudel, el avance de la larga duración. Con la siguiente situación paradójica: por un lado, estaba una historia, la de los historiadores que, atenta a los lectores de la historia y escrutando rupturas durante mucho tiempo invisibles, disminuía la velocidad, y, por otro, estaban los "Treinta Gloriosos" o el "Milagro alemán", años trepidantes de aceleración cada vez más rápida del progreso y de la competencia entre el Este y el Occidente. En sentidos aparentemente contrarios, esos dos movimientos, de los cuales, evidentemente, ni la potencia ni el alcance eran equivalentes, permitían eludir el pasado reciente: mirábamos lejos hacia arriba y hacia otro lado, o nos concentrábamos en tareas urgentes del presente, teniendo en vista el futuro.

Pero, al paso de los años y con la sucesión de generaciones, las grietas, las heridas y las ausencias saldrían a la superficie; las ilusiones también se disiparían. La publicación de Perec, en 1975, de su extraordinaria autobiografía de niño sin recuerdos de infancia, abre plenamente los "años de la memoria". El Austerlitz de W.G. Sebald, para quien el tiempo se había detenido en 1939, ofrecería un equivalente reciente. Desde entonces estamos con esta punzante interrogación: ¿cómo el concepto moderno de historia, intrínsecamente futurista, podría ofrecer un lugar en su estructura misma a ese tiempo desacoplado, suspendido, detenido, a ese pasado que creíamos que ya había pasado sin que así fuese? ¿Olvidado, pero en un olvido que no podíamos olvidar? ¿Cómo el "tren de la Historia" había podido, entonces, conducir hacia el Archipiélago del Gulag (y sus avatares más recientes) y desembocar en la rampa de Auschwitz? De lo cual estamos en el septuagésimo aniversario.

Al final de su libro Zakhor, histoire juive et mémoire juive, publicado en 1982, Yosef Yerushalmi se planteaba: "Ignoro si esta vasta empresa que es la investigación histórica contemporánea se revelará duradera para los judíos y para los no judíos. El anillo del rey Salomón, que debía hacerlo feliz cuando estaba triste y triste cuando estaba feliz, fue fabricado por un joyero que grabó en él estas palabras: "también esto no durará más que un tiempo". Tal vez venga un tiempo en que reinará una 
conciencia nueva que se sorprenderá de que tantos de entre nosotros se hayan sumergido en la historia. A menos que a la historia ni eso le importe. ¿Se acerca ese tiempo? ¿Estamos ya en él? Ni nostalgia, ni catastrofismo, ni profecía improvisada de última hora. Al contrario, de lo que no hay duda es de la transformación de nuestras experiencias del tiempo en el curso de los últimos treinta o cuarenta años, teniendo como signo anunciador el retroceso del futuro; no de todo futuro, sino de ese futuro futurista, el del régimen moderno de historicidad que fue el carbón de la locomotora de la historia. Hablamos rápidamente de "crisis del futuro", de su suspensión, mientras, simultáneamente, el presente tendía cada vez más a tomar lugar.

\section{Nuevas experiencias de tiempo}

Esta transformación de nuestras relaciones con el tiempo ha venido a dibujar una configuración inédita: la que he nombrado presentismo. Como si el presente, el del capitalismo financiero, de la revolución de la información, del internet, de la globalización, pero también de la crisis iniciada en 2008, absorbiera en sí las categorías (tornadas más o menos obsoletas) de pasado y de futuro. Como si, transformado él mismo en su propio horizonte, mutara en un presente perpetuo. Con él se situaron en el primer plano de nuestros espacios públicos las palabras, que son también palabras de orden, de prácticas que se traducen en políticas: memoria, patrimonio, conmemoración e identidad, etc. Ellas constituyen diversas maneras de convocar el pasado en el presente, privilegiando una relación inmediata, haciendo un llamado a la empatía, a la identificación. Para convencerse, basta con visitar memoriales y otros museos de historia, inaugurados en gran número en los últimos años. Además, ese presente presentista se rodea de una cohorte de nociones o de conceptos más o menos destemporalizados: modernidad, post-modernidad, pero también globalización e incluso crisis. Qué es, en efecto, una crisis "sistémica" sino una crisis que dura, que ya no es, entonces, ese momento decisivo que escruta el ojo del médico para establecer su pronóstico. Con la crisis sistémica, estamos atrapados en una suerte de presente permanente: ¿justamente el de la crisis del sistema? Hemos pasado de Hipócrates a Sísifo, cuya piedra no cesa de rodar.

¿Serán estos desplazamientos o este cambio profundo las marcas de un fenómeno transitorio o duradero? Nadie lo sabe aún realmente, aun si la balanza se inclina desde ahora del lado duradero. ¡Las llamadas a "recomenzar" y a salir del "cortoplacismo" son más palabras en el aire que otra cosa! Para el filósofo Marcel Gauchet, ahí se juega "un cam- 
bio de relación con la historia": "ha tomado la forma de una crisis del porvenir en la que el desvanecimiento de la idea revolucionaria no ha sido sino el síntoma más notorio". Con la posibilidad de representarse el porvenir, lo que entra en crisis es la capacidad del pensamiento de la historia de volver inteligible la naturaleza de nuestras sociedades sobre la base del análisis de su porvenir, y de su capacidad de aportarles guías para la acción transformadora de ellas mismas, a título de provisión y de proyecto" (Gauchet, 2005: p. 523). Este cambio de experiencia del tiempo es justamente lo que el concepto (moderno) de Historia no lograba o no logra ya aprehender. Intrínsecamente futurista, ya no es suficientemente operante para entender el devenir de sociedades que, al tender a absorberse entera y solamente en el presente, ya no saben cómo ajustar sus relaciones con un futuro percibido comúnmente cada vez más, al menos en Europa, bajo el modo de la amenaza, incluso de la catástrofe por venir o en marcha.

Ese futuro ya no se concibe como indefinidamente abierto sino, al contrario, como cada vez más coaccionado, incluso cerrado, debido, en particular, a la irreversibilidad generada por la serie de nuestras acciones. Pensamos en seguida en el calentamiento climático, en los desechos nucleares, en las modificaciones de los seres vivos, etc. Descubrimos, de forma cada vez más y más acelerada y cada vez más precisa, que el futuro no solamente se extiende cada vez más lejos de nosotros, sino que lo que hoy hacemos o no hacemos tiene incidencias sobre ese futuro tan lejano que ya no representa nada a la escala de una vida humana. En el otro sentido, hacia atrás, hemos aprendido que el pasado viene de lejos, de cada vez más lejos (la época de la aparición de los primeros homínidos no deja de retroceder, mientras que la edad del universo se aproxima ahora a los catorce mil millones de años). Confrontados con estos cambios radicales de nuestros puntos de referencia, nos sentimos tentados a decir jalto!, a proponer una vuelta atrás, a encontrar el paraíso perdido. La industria del entretenimiento comprendió inmediatamente la ventaja que podría obtener de islas paradisiacas y de otros territorios vírgenes donde el vacacionista compra experiencias bien calibradas de desaceleración programada. En cuanto a las amenazas y los miedos que dichos cambios pueden alimentar, pueden transplantarse a una nueva forma de "terror" de la historia, recordando, pero con otras expectativas, este "terror" que se volvió una suerte de leitmotiv para el pensamiento de Mircea Eliade, quien militó en la extrema derecha en la década de 1940 (Eliade, 1949). Cierto ecologismo radical o fundamentalista iría en la misma dirección. En cuanto al pasado histórico, tendemos a "tratarlo" o a "gestionarlo" en lugares precisos (los tribunales) y por 
medio de acciones específicas (las políticas memoriales). Ya sea en el presente y por el presente, o bajo la autoridad de la memoria.

\section{Las temporalidades}

del concepto de Historia

Encargado del tiempo, el concepto de historia ha sido el receptáculo de varios estratos temporales o, por tomar otra imagen, está tejido de varias temporalidades. El estrato más antiguo es el que va del pasado hacia el presente, que corresponde al antiguo régimen de historicidad. Durante siglos, éste gobernó el gran registro de la historia magistra vitae. Si el advenimiento de la temporalidad moderna lo hizo perder su primacía, no lo hizo, sin embargo, desaparecer, ya que el antiguo topos de las lecciones de la historia ha permanecido disponible, susceptible de ser reactivado. Y no ha dejado de ocurrir, incluso con más insistencia actualmente dentro del marco de las conmemoraciones. Es el registro de la ejemplaridad, de la imitación y del deber ser. ¿Con qué eficacia, con qué efecto sobre la realidad aún recurrimos a eso? He ahí la pregunta. Incluso cuando el concepto de historia, abriéndose al tiempo futurista, había tomado distancia frente a esta antigua y poderosa acepción. Esta temporalidad se volvió como un combustible del concepto moderno de historia, de esta locomotora en marcha cada vez más rápida, a pesar de las interrupciones, las fallas y los descarrilamientos. Mientras el marxismo o la revolución permanecieron como "el horizonte infranqueable", como decíamos, la Historia y la historia eran homólogas. La historia era la ciencia de lo real y la experiencia histórica tenía sentido. Estábamos, con seguridad, encaminados hacia el porvenir, un porvenir que debía ser esperado al máximo, pero más allá del cual no nos podíamos proyectar o autorizarnos a pensar. Después se abriría el otro tiempo apocalíptico: el nuevo cielo y la nueva tierra finalmente comunistas. Durante varias décadas la URSS significó, para los comunistas del mundo entero, el advenimiento de nuevos tiempos.

Entre las situaciones históricas y el concepto de historia siempre ha habido tensiones, ya sea que el concepto esté en conexión con una coyuntura o que esté desfasado respecto de ella. En conexión, ese concepto puede dar la impresión a quien lo maneja de aprehender correctamente la situación y que puede hacer historia, hacer historias o, simplemente, dar sentido a su experiencia histórica. El desfase puede deberse a que el concepto adjudica demasiada importancia al pasado o, inversamente, al futuro. Aquel que lo utiliza quisiera, por ejemplo, volver a un pasado que ya no es, o impulsarse más rápido hacia un porvenir que aún no existe. 
Tanto en un caso como en el otro se activan temporalidades heterogéneas y, por tanto, constitutivas del concepto, para describir, comprender, hacer ver una situación. Si el desfase es muy grande, la toma no será buena y el resultado será borroso, como una fotografía movida. Se vería el presente con los lentes del pasado: el riesgo es, entonces, "entrar en el porvenir yendo hacia atrás", por retomar una vez más una expresión de Valéry. Con los lentes del porvenir, el riesgo es hacer como si éste ya hubiera sucedido a partir del día en que declaramos la apertura de una nueva era. En seguida viene la situación, más o menos irreprimible, de barrer "el legado". El enemigo no es el desfase, sino un desfase excesivo. Entre una realidad y su concepto, o entre lo real y la manera en que el concepto lo retoma, hay siempre una distancia: a fortiori cuando se trata de esta realidad reconstituida que es toda situación histórica. Es incluso en esta distancia que se alberga la posibilidad de volver a trabajar el concepto y de afinar la aprehensión de la situación: de ver más y mejor el presente, en función del pasado y del porvenir, es decir, en el caso del concepto moderno de historia, en función de la luz proyectada por el futuro sobre el pasado, con la finalidad de volverlo inteligible.

Historia es, en el fondo, un nombre venido de lejos que hemos escogido para reunir y mantener juntas las tres dimensiones del pasado, el presente y el futuro. Para mostrar e interrogar lo que las reúne y las separa, con todas las combinaciones posibles que puede hacer quien las maneja (un individuo, un grupo, una institución, el Estado) a partir de su situación presente, y para actuar sobre ellas directa o indirectamente (por ejemplo, a través de la escuela o las conmemoraciones). Una vez puesto en marcha por Heródoto, el nombre fue adoptado y no ha cesado de ser retomado, corregido, modificado, amplificado, elogiado, enaltecido, mofado, denigrado, recusado, etc., pero siempre ha permanecido ahí: inmediatamente disponible. Hoy, sin embargo, Mnemosine ha suplantado a Clío, al menos en el espacio público.

\section{Memoria y ausencia}

En La mémoire, l'histoire, l'oubli, su último libro, Paul Ricoeur se proponía salir del cara a cara estéril entre historia y memoria, con su cohorte de defensores y de detractores, recusando al mismo tiempo toda subordinación de la segunda respecto de la primera. Él quería una historia "tomada" por la memoria, pero no una memoria reducida a "objeto de historia". Porque él sostenía que, por su "poder de comprobación" de que un pasado tuvo lugar, la memoria debe ser tomada por "matriz" de la historia. De esta posición se sigue la conclusión, frecuentemente retomada después, sobre 
la imposibilidad de dividir, "en el plano gnoseológico", "la competencia entre un deseo de fidelidad de la memoria y la búsqueda de la verdad en la historia" (Ricoeur, 2000: p. 502). La decisión vuelve al lector, es decir, al ciudadano que, una vez informado y consciente de estar en deuda respecto de sus predecesores, hará "el balance entre la historia y la memoria". Por eso hay, forzosamente, una "inquietante extrañeza" de la historia, por eso Ricoeur puede, recurriendo a Platón, presentarla como ese farmakon, remedio y veneno al mismo tiempo, ya que no puede "exorcizar la sospecha" de que la historia sea, en el fondo, un "daño para la memoria" (Ricoeur, 2000: p. 179). Michel de Certeau reconocía, por su parte, lo que él designaba como "la inquietante familiaridad de la historia". Tomando la ausencia como razón de ser, ella se escribe, efectivamente, ocupando el lugar de lo que ya no es. Como decía Michelet, ella entierra a los muertos para hacer un lugar a los vivos, en la medida en que "una sociedad se dota de un presente gracias a la escritura histórica" (Certeau, 1975: p. 119), un presente no cerrado sobre sí mismo, sino abierto hacia un futuro, informado por sí mismo, capaz de un proyecto.

El modelo micheletiano de historia, incluso con el historiador como visitante de los muertos, seguía siendo plenamente compatible con el régimen moderno de historicidad porque estaba atravesado por el aliento de la Revolución y guiado por la marcha hacia adelante del Pueblo. Pero cuando la muerte se transformó en una industria, cuando los muertos fueron borrados tan minuciosamente como fue posible, cuando el tiempo se detuvo, cuando poco a poco tomamos conciencia de que el pasado no pasaba, ¿en qué se convertía la historia, el concepto moderno de Historia? ¿Cómo podía modularse el hacer historia y cómo dar aún sentido a la experiencia histórica? Porque, ¿cómo enterrar a los muertos golpeados, por así decirlo, por una ausencia intensificada? ¿O cómo "hacer un lugar a los vivos", si la distancia entre el campo de experiencia y el horizonte de espera se ha acrecentado hasta casi una ruptura entre los dos o, peor, si el horizonte de espera ha adoptado el rostro de la catástrofe? Incluso de una doble catástrofe: desde la que viene, la que está en marcha, la que esperamos, hasta aquella que tuvo ciertamente lugar, de la cual tuvimos la experiencia; todo en un mismo presente. Horizonte de espera y campo de experiencia se comunican por intermediación de la figura unificadora de la catástrofe. Para plantear esas preguntas, plantearlas en esos términos, hizo falta que pasara el tiempo en nuestras sociedades. El último medio siglo se empleó difícilmente en ello. Escritores, filósofos, historiadores, políticos, instituciones, encontraron esas preguntas, las afrontaron, incluso las evitaron (a veces giraron en torno a ellas, como un navío que se aferra a permanecer anclado, a pesar del viento y de la corriente). 
La memoria, la conmemoración, el patrimonio, la identidad se volvieron, así, las palabras maestras de finales del siglo $\mathrm{xx}$, aun cuando la Historia, la divinidad mayor de Europa desde el siglo XIX, veía desvanecerse su magisterio, tanto en su "suelo" como en todas esas tierras que a través de sus misioneros, sus comerciantes, sus soldados, sus administradores y sus eruditos; ella había emprendido "convertir" a su modo de vida histórico. De hecho, el deslizamiento de la historia a la memoria durante la década de 1980 indicaba un cambio de época, expresando un regreso hacia los "restos del navío" que Febvre exhortaba a abandonar rápidamente en 1946 y que habían permanecido entre dos aguas. Lo mismo ocurre con el patrimonio, que es una noción para tiempos de crisis. Cuando los puntos de referencia se derrumban, cuando la aceleración del tiempo acentúa la desorientación, buscamos preservar lugares, objetos, gestión, con la finalidad de volver habitable un presente en el que ya no nos encontramos a nosotros mismos. La conmemoración es la expresión pública del fenómeno memorial. Ella da lugar a políticas memoriales (en Europa), y hasta a "leyes de memoria". En cuanto a la identidad, centro organizador de esas nociones, es doblemente portadora de una inquietud: sobre el pasado (¿cuál es, en verdad, el pasado de Francia?), sobre el futuro (¿cuál puede ser nuestro porvenir común?), ¿de qué esperanza puede ser (aún) portadora Europa?

\section{La experiencia de las catástrofes}

El Ángel de la Historia, sobre el que Walter Benjamin planteó su novena tesis sobre la historia, se situaba en la transición del apocalipsis a la catástrofe (Benjamin, 2001). Con el ángel y su visión sinóptica de la historia estamos aún, en efecto, dentro de un dispositivo apocalíptico. Pero, llevado por el viento del progreso, el ángel "le da la espalda al porvenir". Cambiamos de registro. En efecto, la historia ya no es progreso sino, al contrario o simultáneamente, marcha ininterrumpida hacia la catástrofe. No es, ya lo sabemos, la última palabra de Benjamin en la materia, ya que sus tesis tenían por objeto reabrir la posibilidad de un tiempo mesiánico, que es también el de la acción revolucionaria y de la emancipación.

"Catástrofe" fue durante mucho tiempo una palabra del vocabulario literario que significaba el desenlace desafortunado y funesto de un poema dramático. No fue sino hasta la época moderna, en el siglo XIX, destacaba Pierre Larousse, cuando tomó el sentido de "desgracia decisiva". A diferencia del apocalipsis que es, me atrevo a decir, un fusil con una sola bala, la catástrofe es susceptible de repetirse. Hemos entrado incluso, 
digámoslo concretamente, en el "tiempo de las catástrofes" (climática, sanitaria, nuclear u otra), que tiende a imponerse como el horizonte de nuestra experiencia histórica. ${ }^{5}$ Por ello, queremos indicar que hay un vínculo entre las catástrofes y lo que las enlaza, entre lo que hicimos, hacemos o, más aún, lo que aplazamos o nos rehusamos a hacer. De la toma de conciencia de lo que comienza a ser percibido como una nueva condición histórica se derivan propuestas de reconsiderar completamente la Historia moderna. Ya no es conveniente verla como la historia del progreso, cuyo ritmo fue marcado por las sucesivas revoluciones industriales, sino como una nueva era geológica. Esta geo-historia, denominada ahora Antropoceno, comenzaría precisamente en 1783, con la máquina de vapor de James Watt (Bonneuil \& Fressoz, 2013). Es decir, cuando el impacto de la acción humana sobre el sistema de la Tierra se vuelve cada vez más marcado y, sobre todo, cuando desencadena una irreversibilidad. Tanto que hoy en día, después de poco más de dos siglos, nos encontramos en la situación inédita de haber iniciado un nuevo tiempo mesiánico, pero negativo, teniendo en el horizonte un apocalipsis posible que hay, por lo menos, que retrasar, desviar y, si es posible, evitar. Esta propuesta vuelve a tomar a contrapelo toda la historia llamada moderna, reescribiéndola en su totalidad.

Entre quienes primero despertaron o lanzaron la alerta podemos citar a Günther Anders, uno de los primeros en cuestionar nuestra "ceguera ante el apocalipsis". Aunque él meditaba sobre las consecuencias de la bomba, no podía aún prever la cuestión inédita que iba a plantear el tratamiento de los desechos nucleares. Hans Jonas, por su parte, formuló su "principio de responsabilidad", movilizando sin dudar el miedo. JeanPierre Dupuy, como lector de Anders y de Jonas, construyó su teoría de "catastrofismo ilustrado" (Anders, 2002; Jonas, 1990; Dupuy, 2002). Verlos a ellos como apocalipsistas sería hoy erróneo. En última instancia, están más del lado de los profetas, de aquellos que anuncian lo que va a suceder, salvo si... Pero nuestras sociedades europeas que envejecen, minadas por la crisis, vacunadas contra los futurismos, atrapadas en el presentismo, están preocupadas por lo inmediato y tentadas por el repliegue sobre sí mismas, aun cuando el capitalismo no puede poner el beneficio del hoy al servicio del mañana, y no puede no maximizar el beneficio del hoy.

5 Ver, por ejemplo, Esprit, marzo-abril de 2008, "Le temps des catastrophes"; en particular, Jean-Louis Schlegel, "L'eschatologie et l'apocalypse dans l'histoire: un bilan contrasté". 


\section{Historia y globalización}

La pérdida de la creencia en la historia, ¿es un fenómeno local (francés), regional (europeo) o mundial? La Francia que se salió de la historia, o la España que mira pasar la historia desde su ventana, es algo que leemos u oímos repetir aquí y allá. Por una parte, los estudios postcoloniales se empeñaron en profundizar las expectativas de esa constatación inicial, que terminó por resumirse en la "provincialización" de Europa de Dipesh Chakrabarty, mientras que aquí se puso en circulación una literatura rápidamente bautizada de "declinista". Pero una respuesta que no fuese impresionista ante la pregunta acerca de la creencia o la incredulidad necesitaría una vasta investigación, que yo no he llevado a cabo y, que yo sepa, nadie ha emprendido. Además, no sería fácil llevar a cabo tal investigación: ¿cómo medir la creencia o la incredulidad? Y, para empezar, ¿qué evoca hoy en el mundo el vocablo historia? ¿Qué decimos cuando lo usamos o cuando preferimos el de memoria? Aun cuando hay tantas formas (por la imagen, antes que nada) de hacer un llamado al pasado o de fabricar pasados, tal como muestra el inventario de Serge Gruzinski en su último libro. ${ }^{6}$ ¿Qué respuesta dar, a pesar de todo? Tal vez ésta. Hubo, por una parte, la Historia, aquélla en que Europa creyó, la que teorizó, que impuso, haciendo de ella el patrón y el telos de todas las otras. En general, aquella que estaba marcada por el progreso, que caminaba hacia el futuro y que daba sentido a la experiencia histórica. Aunque ya no rija, no se desvaneció, sin embargo, de un día a otro. Además, no ha dejado de dar lugar, aquí y allá, a toda suerte de negociaciones que van de su aceptación a su completo rechazo, pasando por reformulaciones múltiples, sin olvidar las instrumentalizaciones más o menos burdas a las que se presta más o menos de buen grado. De ello hubo, en el curso del siglo XIX y del XX, toda una gama de modalidades. La historia-disciplina, que aspiraba a presentarse como ciencia, tuvo que encargase de esas modalidades organizándolas como una música, bajo la forma mayor de partituras nacionales por todas partes en el mundo.

Encontramos, por otra parte, el presentismo contemporáneo, el del instante y de la simultaneidad, el que ha modelado nuestra nueva "condición digital" (Fogel \& Pattino, 2013). Es el corazón y el motor mismo de la Globalización, a semejanza del futurismo en la Historia de antaño. Como la Historia (con H mayúscula), la Globalización (con G mayúscula)

\begin{tabular}{l|l}
6 & En la segunda parte del libro reúne sus propuestas sobre lo que debería ser una histo- \\
ria global.
\end{tabular} 
se presenta desde ahora como una evidencia: es indiscutible. ${ }^{7} \mathrm{El}$ lema es "No hay alternativa". Es al mismo tiempo el porvenir y el pasado, ya que para quien se toma el tiempo de ver de cerca, siempre ha estado ahí. Hubo globalización desde que hubo intercambios, redes, conexiones, con esplendores más o menos grandes e intensidades más o menos fuertes, haciendo que se comunicaran lo local y lo global, más precisamente, lo local de un lugar con lo local de otro, produciendo así algo que los sobrepasa a uno y a otro. Es el buen nivel, el buen punto de vista.

Habiendo abandonado el evolucionismo y las teleologías providenciales, nacionales o de clase, la nueva práctica de la historia se despliega en el espacio-mundo, se mueve en lo contemporáneo de lo contemporáneo y se apega a construir una simetría. De tal suerte que observamos bien cómo la Globalización podría aparecer como el nuevo nombre del concepto de historia o como el nombre mismo de la Historia, una vez que ella ha renunciado a la difunta seguridad del eurocentrismo y adoptado la polifonía. Es el nombre que viene a tomar el relevo de un concepto extenuado: la Globalización o la Historia, la historia global, entonces; es decir, la historia verdadera. Sería, en suma, una operación que se ha vuelto indispensable de sustitución (y primero de reparación) y un ejercicio de lucidez. A un mundo nuevo, a una nueva experiencia histórica, le corresponde una nueva historia de ayer y de hoy, para hoy (Hartog, 2013a: pp. 271-280).

Quizá, sin ser falsa, esta vista general es, sin embargo, poco esquemática una vez que entramos en las negociaciones concretas, que tienen lugar desde hace unos veinte años, entre una historia que aspira a lo global y la disciplina histórica entendida como institución. ¿Se trata de una nueva historia o de una nueva especialidad que busca ser alojada bajo el amplio paraguas de la historia? Es así como ha buscado, para empezar, reconocimiento y legitimidad: como una nueva aproximación y como una nueva problemática. Más aun cuando los primeros historiadores "globales" eran autodidactas o conversos: al principio eran historiadores de otra cosa. En el año 2000, con motivo del Congreso Internacional de Ciencias Históricas en Oslo, los organizadores encontraron que la historia global estaba "todavía en pañales" y sus practicantes eran aún relativamente pocos. Además, la terminología no estaba aun completamente estabili-

Desde una posición escéptica, Sanjay Subrahmanyam afirma: "Hay que tratar la cuestión en relación con los debates actuales sobre la globalización y sus orígenes propuestos, por un lado, por los teóricos del sistema-mundo o por los economistas neoliberales del National Bureau of Economic Research, por el otro. Por mi parte, permanezco agnóstico sobre la utilidad del concepto de "globalización" como sobre toda poción mágica con un fuerte contenido teleológico" (2013: p. 24). 
zada, ya que hablábamos de historia universal, de historia mundial o de historia global (Sogner, 2001: p. 11; O'Brien, 2001). Para Sanjay Subrahmanyam, titular de la Cátedra de Historia global de la primera modernidad recientemente abierta en el Colegio de Francia, la respuesta no deja lugar a dudas. La historia global es una "variedad" complementaria de la historia, a la que se puede pedir todo lo que puede dar, pero no más. "Hay un interés y una curiosidad que se incrementan por este tipo de historia, que no está destinada, sin embargo -es mi convicción profunda- a reemplazar a la historia hecha a escala regional o continental, sino que la completa. Igualmente, estoy convencido de que podemos encontrar nuevas sinergias, combinando esas variedades de historia bajo el mismo techo" (Subrahmanyam, 2013: p. 28).

Pero, si dejamos el terreno de los compromisos disciplinares, ¿la historia global tiene la vocación de ser más que eso? ¿De remodelar la casa entera, de imponerse como el concepto de historia que, al hallarse en sintonía con el mundo de hoy, permite retomar todo: de reescribir lo que fue escrito y de escribir lo que no lo ha sido, dando sentido a la experiencia histórica contemporánea? Aún no hay nada establecido, incluso si en quince años la historia global ha ganado (globalmente) el partido, empezando por el nombre. En una disciplina amante de los cambios, podemos, al menos, reconocer un giro global de la historia. ¿La disciplina está en consonancia, atrasada o adelantada respecto a la experiencia histórica? ¿La historia global puede volverse portadora de una nueva creencia en la historia? ¿Lo ambiciona? ¿Su concepto tiene la capacidad de hacerlo? Hay muchas preguntas aún abiertas.

\section{Pasado, presente, futuro}

En lo que yo nombro el antiguo régimen de historicidad (antes de 1789, por tomar una fecha simbólica), los actores sociales tenían, ciertamente, su presente, vivían en ese presente, intentaban comprenderlo y manejarlo (Hartog, 2012). Pero para orientarse y dar sentido a su experiencia histórica comenzaban mirando del lado del pasado, con la idea de que era portador de inteligibilidad, de ejemplos y de lecciones. Y la historia era el inventario de esos ejemplos y la narrativa de esas lecciones. En el régimen de historicidad futurista, o régimen moderno, sucedía lo inverso: mirábamos del lado del futuro, que iluminaba el presente y explicaba el pasado; había que ir de prisa hacia él. Él orientaba las experiencias históricas y la historia era teleológica: el objetivo indicaba el camino ya recorrido y el que faltaba por andar. Todas las historias nacionales modernas fueron concebidas y escritas bajo este modelo. 
La singularidad del régimen presentista radica en que no hay, finalmente, más que presente. Cada quien puede tener esa experiencia en su vida cotidiana, tanto personal como profesional. En este régimen, no sabemos qué hacer del pasado, ya que no lo vemos más, y no sabemos qué hacer del porvenir, pues ya tampoco lo vislumbramos. No quedan más que acontecimientos que se suceden o que se interrelacionan, ante los cuales hay que "reaccionar" de urgencia, al ritmo incesante de bandas que desfilan con "Breaking News". Con la Internet se ha impuesto en tiempo real la simultaneidad de todo con todo y su continuo. Todo aparece en el mismo plano, en un presente tan extendido como la red misma. En esta nueva condición numérica, resulta más problemático que nunca articular pasado, presente y futuro, pero aparece como cada vez más necesario hacerlo, aunque sobre el trasfondo de la globalización parezca alejarse la posibilidad de un relato común: a cada uno su memoria, su sitio y su blog, según un incesante y cambiante incremento. La historia, tanto local como global, si quiere tener un efecto en el mundo, deberá tomar en cuenta esas nuevas experiencias de tiempo, aplicándose a hacer surgir de la aparente contemporaneidad de todo con todo las diferentes temporalidades activadas en el seno de un mismo presente que todo lo atrapa.

\section{Bibliografía}

Anders, G. (2002)

L'obsolescence de l'homme, París: Éditions Ivrea.

Benjamin, W. (2001)

"Sur le concept d'histoire", edición de Michael Löwy, Avertissement d'incendie. Une lecture des thèses "Sur le concept d'histoire ", París : PUF, pp. 71-77.

Bonneuil, C. y J-B Fressoz (2013)

L'événement anthropocène, la Terre, l'histoire et nous, París : Seuil. Certeau, M. de, (1975)

L'Écriture de l'histoire, París : Gallimard.

Dupuy, J-P. (2002)

Pour un catastrophisme éclairé, París: Seuil.

Éliade, M. (1949)

La terreur de l'histoire, París : Gallimard.

Febvre, L. (1992)

Face au vent, Manifeste des Annales nouvelles, en Combats pour l'histoire, París : Armand Colin.

Fogel, J-F. y B. Pattino (2013)

La condition numérique, París: Grasset. 
Gauchet, M. (2005)

La condition politique, París: Gallimard.

Gauchet, M. (2003)

La condition historique, París: Stock.

Gruzinski, S. (2015)

L'Histoire, pour quoi faire? París: Fayard.

Hartog, F. (2013a)

Croire en l'histoire, París: Flammarion.

Hartog, F. (2013b)

"The Modern Régime of Historicity in the Face of Two World Wars", en Chris Lorenz y Berber Bevernage (ed.) Breaking up Time, Göttingen: Vandenhoech \& Ruprecht, pp. 124-133.

Hartog, F. (2010)

"Le présent de l'historien", en Le Débat, 158, pp. 18-31.

Hartog, F. (2012)

Régimes d'historicité, Présentisme et expériences du temps, París:

Point-Seuil, edición corregida y aumentada.

Jonas, H. (1990)

Le principe de responsabilité, París: Cerf.

O'Brien, P. K. (2001)

"The Status and Future of Universal History", en Sogner, Solvi (ed.)

Making sense of Global History, Oslo: Universitetsforlaget, pp. 15-33.

Revel, J. (2006)

Un Parcours critique. Douze exercices d'histoire soicale, París: Galaade.

Perec, G. (1975)

W ou le souvenir d'enfance, París: Gallimard.

Ricoeur, P. (2000)

La Mémoire, l'Histoire, l'Oubli, París: Seuil.

Rioux, J-P. (2015)

Vive l'histoire de France! París: Odile Jacob.

Schlegel, J-L. (2008)

"L'eschatologie et l'apocalypse dans l'histoire: un bilan contrasté", en

Esprit, número especial Le temps des catastrophes, pp. 88-103.

Palmié, S. y C. Stewart (s/f).

"The Varieties of Historical Experience", manuscrito.

Subrahmanyam, S. (2013)

Aux origines de l'histoire globale. Leçon inaugurale au Collège de France (recuperado de http://books.openedition.org/cdf/3606).

Recibido: 20/04/2016. Aceptado: 14/09/2016 